\title{
Procurement of information technology as an integral part of business process improvement
}

\author{
H. Sundmaeker \\ ATB Institute for Applied Systems Technology Bremen GmbH \\ Wiener Str. 1, 28359 Bremen, Germany \\ Tel.: +49-421-22092-53 \\ Fax: +49-421-22092-10 \\ e-mail:Sundmaeker@atb-bremen.de
}

\begin{abstract}
Each Business Process Improvement activity aims besides others in increasing quality or productivity. Within the realisation of these abstract aims, improvement projects which are resulting in introduction of new production management systems often fail in the phase of implementation. Advances as planned could not be realised and the break even point is far away. Different approaches exist to improve procurement but are often not applied, due to their complexity and the daily work of the responsible staff. This paper presents the improvement scope of existing approaches and in detail new methods to increase the success rate of procurement.
\end{abstract}

Keywords

Procurement, Acquisition, Best Practice, Improvement, Implementation, Information Technology, Business Process

\section{INTRODUCTION}

The globalization of the market place and improved supply chain management urges enterprises to expand their business by introducing new Production Management Systems to optimise business processes and handle decentralised organisations. Such improvements must be managed as a project, due to e.g. complex organisation structures, the number of workplaces to be implemented and amount of data to be handled. To manage a high complex procurement/acquisition project over one year must be assumed, CCTA (1995), to realise the targeted solution as defined during the initial phase. To manage such a project systematically several 
guidelines propose similar approaches like the one shown in Table 1 taken from the PULSE methodology (1999) (see section 3.2) which is compatible to ISO/IEC TR 15504 (1998).

Table 1: Acquisition Processes of the PULSE methodology

\begin{tabular}{|c|c|c|c|}
\hline \multicolumn{4}{|c|}{ Acquisition Processes } \\
\hline Identifier & Process & Identifier & Sub-Process \\
\hline \multirow[t]{4}{*}{ ACQ.1 } & Acquisition Needs & & \\
\hline & & ACQ.1.1 & Acquisition Policy \\
\hline & & ACQ.1.2 & Acquisition Strategy \\
\hline & & ACQ.1.3 & Benefits Analysis \\
\hline \multirow[t]{5}{*}{ ACQ.2 } & Requirements Definitio & & \\
\hline & & ACQ.2.1 & Technical Requirements \\
\hline & & ACQ.2.2 & Contract Requirements \\
\hline & & ACQ.2.3 & Financial Requirements \\
\hline & & ACQ.2.4 & Project Requirements \\
\hline \multirow[t]{4}{*}{ ACQ.3 } & Contract Award & & \\
\hline & & ACQ.3.1 & Invitation to tender \\
\hline & & ACQ.3.2 & Tender Evaluation \\
\hline & & ACQ.3.3 & Contract Negotiation \\
\hline \multirow[t]{4}{*}{ ACQ.4 } & Contract Performance & & \\
\hline & & ACQ.4.1 & Supplier Monitoring \\
\hline & & ACQ.4.2 & Acquisition Acceptance \\
\hline & & ACQ.4.3 & Contract Closure \\
\hline
\end{tabular}

Methods and strategies to apply e.g. Procurement Best Practices must be defined to optimise the implementation of new systems. Guidance is provided through methods and guidelines such as e.g. Euromethod or Total Acquisition Process (TAP) (see section 3.1.1) for Best Practice based improvement. Many project managers will ask: "How to apply an abstract process model?". This indicates the need for Best Practices which can be found in the own organisation or in external guidelines for Best Practice based improvement. External experience provides guidance on e.g. Best Practices, but not on their impact on the project results and moreover not guarantees that all recommendations given, are Best Practices. This was the starting point of the project VALIDATE (see section 3.1 and 6.) and which identified nearly 400 Best Practices in well known Procurement Guidelines (section 6.). This paper describes furthermore different ways to improve and manage the procurement of information technology like production management systems (e.g. PPM-Systems) to ensure the delivery of improved business processes as result of well managed IT procurement. 


\section{PROCUREMENT PROCESS IMPROVEMENT AS A RESULT OF BUSINESS PROCESS IMPROVEMENT}

Enablers of process improvement are driven by business goals (e.g. cost reduction, increased productivity, reduction of time to market) or by problems known with respect to processes applied (e.g. insufficient documentation, risk management or management of customer needs). Setting up an improvement project often results in the identification of the need to introduce new integrated Information Technology to increase efficiency, effectiveness and competitiveness. The business process improvement project therefore often results in a procurement project which has to be performed according to the defined business goals or known problems.

Increased functionalities and complex modern systems are prerequisites for the realisation of the business goals, but without a well managed procurement project, risks related to an introduction could jeopardise the whole improvement project.

A business improvement/procurement project could be divided in three major steps:

- Analysis (e.g. benefits, strategy),

- Requirements definition (e.g. technical, financial),

- Selection (e.g. call for tenders, contract negotiation), and

- Implementation (e.g. introduction, acceptance).

Procurement Process Improvement supports therefore organisations in how to ensure the realisation of business benefits as originally planned according to the budget, schedule and quality requirements within all project phases. Due to the complexity of such projects no priority could be given, which indicates the importance of different phases or of company aspects (i.e. technology, organisation, skills), since each element can jeopardise the realisation of benefits sought. But the negative impact of faults made during the project course on productivity after final implementation is dependent on the time needed from identification or change request to the delivery of an e.g. new release of the system. Furthermore correlates the length of the "fault correction time" with the phase in which the fault was caused.

\section{INTRODUCTION OF PROCUREMENT PROCESS IMPROVEMENT}

Considerable efforts have been invested in defining procurement guidelines and methodologies, available as electronic or paper based references, but successful procurement processes are still difficult to achieve. The application of guidelines and methodologies facilitate the organisation and management of procurement projects but do not directly identify the critical aspects or practices to ensure the achievement of the defined business benefits and implementation success.

To introduce and apply procurement process improvement, the organisation has to firstly collect and organise the reuse of internal experience and should identify relevant external sources of material available on procurement, such as 
- Best Practice guidelines,

- methodologies,

- standards for selection and evaluation, and

- assessment methodologies.

Such sources of external experience gained, should be combined with internal human knowledge and skills and be available to all involved parties structured to enable the 'procurer' to identify critical bottlenecks and to solve known problems.

\subsection{VALIDATE - Comparison and Validation of Best Practices for procurement}

The VALIDATE project started with an analysis of twelve procurement references (e.g. TAP, BuyIT, EPHOS, R5000-2) and a set of nearly 400 Best Practices were identified. These practices were structured according to the management, administrative, technical and user function within an organisation. To assess the impact of these practices w.r.t. the procurement results, thirteen organisation throughout Europe were interviewed. In the first interviews it was identified which practices these organisations are applying within real IT procurement projects, followed by interviews to determine the results of these projects. The collected results were used to identify the relationship between the applied practices and positive or negative procurement results. As expected, it turns out, that every procurement result correlates with multiple procurement practices. However, the most remarkable findings within the VALIDATE project could be outlined as follows:

- several practices turned out to have a negative impact on procurements,

- a set of 25 top practices could be identified, and

- not all procurement processes are covered with the same amount of procurement practices.

Even a commonly applied practice like "Give preference to commercial off-theshelf software" seems to influence complex projects negatively. But on the other hand one of the top practices as e.g. "Identify training requirements within requests for proposals." seems to influence the success rate by e.g. increased productivity and better staff motivation. Besides the impact of procurement practices, the following diagram (Figure 1) shows that the different procurement processes are not sufficiently covered in the analysed guides. 


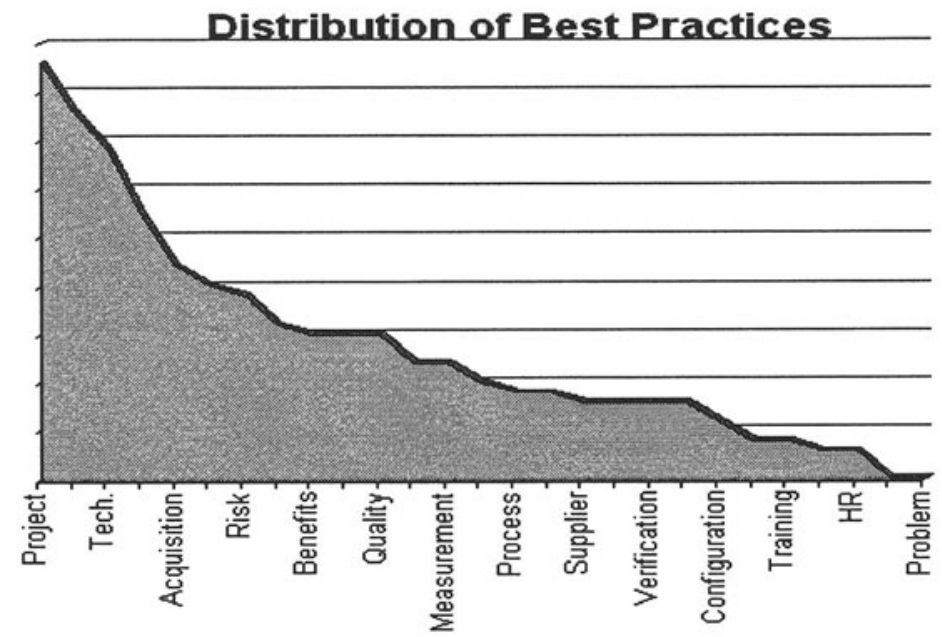

Figure 12: Distribution of Best Practices

The 'uncovered' processes are primarily areas related to the day to day management and conflict resolution of projects, such as monitoring supplier performance, ensuring supplier quality, establishing procurement procedures and tracking, and supplier conflict resolution, especially processes in the later stages of a procurement where problems most often arise. To compensate this situation, a procuring organisation could use on the one hand Software Engineering guides strongly targeted towards the "implementation processes" and on the other hand should intensify the teamworking aspect with suppliers to establish as soon as possible a close co-operation to facilitate the implementation of complex systems.

\subsubsection{TAP - Total Acquisition Process}

TAP, CCTA (1995), one of the analysed guidelines within the VALIDATE project, provides guidance mainly for major IT and public sector procurements. "The overall aim of TAP is to improve the success rate of Government IS/IT projects ... It is based on the Total Acquisition Process (TAP), first introduced following a review of Government IS/IT procurement procedures in 1990/1991." There are two guides available. The first aiming in procurement of IT Systems and the second in Services. These guides are a good reference and starting point to improve procurement. The guide gives a good overview of all steps and activities to be considered, also with reference to low, medium and complex procurements. Also lists of the different procurement steps recommended, examples of requirements specification, a checklist for requirements and evaluation models are given. But besides all this information "Staff resources applied must be skilled and experienced." Mottram. (1995) and improvements in the short term are difficult to achieve. 


\subsection{PULSE - ICT acquisition process assessment methodology}

The PULSE methodology also provides support to improve IT procurement, but starts from a different point of view. It is a framework for assessing the procurement (in PULSE named acquisition) processes (see Table1) of commercial and public organisations and is structured with its various components as follows:

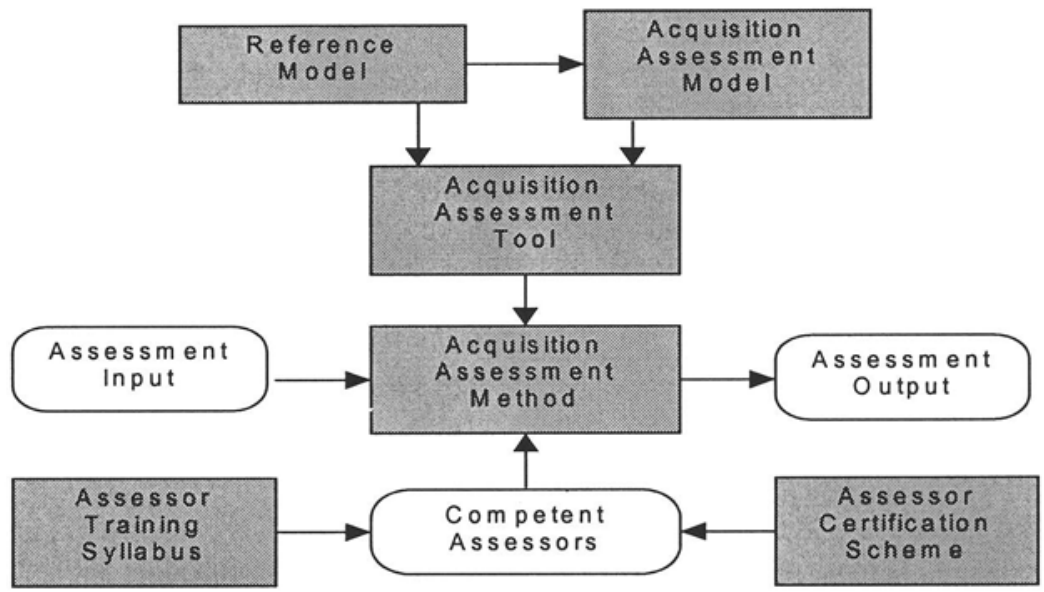

Figure 13: Components of the PULSE Methodology

PULSE combines two approaches to improve procurement. (a) By performing an initial assessment the organisation can enter an ongoing improvement cycle, to concentrate at the first stage in the improvement of the most promising and limited areas. (b) The Capability Determination of procurement processes as follow up of already performed assessments to identify the next steps or as basis to identify areas of improvement by benchmarking the achieved results with a benchmarking database. By using the "generic acquisition process model" of PULSE, the resulting assessment profile accommodates the fact that:

- not all processes need be present in every procuring organisation, and

- organisations may have very different acquisition profiles depending on factors such as their industry, how they use IT, the type of IT they procure, and their specific business goals and objectives.

The three essential and available components of the PULSE methodology, the ICT Acquisition Assessment Model, Method and Tool providing the opportunity to perform a range from independent (third party) up to self assessments. Within the course of the PULSE project, assessments with European user organisations were performed and the first results were collected to establish an European procurement benchmarking database. 


\section{APPROACH FOR THE INTRODUCTION OF PROCUREMENT P ROCESS IMPROVEMENT}

Specific improvements in the short-term and the application of practical methods will effect traceable results and increase the motivation of the staff affected. This requires awareness w.r.t. the processes performed, risky routes, possible bottlenecks and detailed procurement practices to identify and plan effective improvements. This knowledge based approach to plan improvement (i.e. use of internal and external experience gained) must be structured according to an "implementation pyramid" (i.e. implementation according to organisational level) of the organisation as follows:

Table 2: Implementation pyramid to plan and structure improvement activities

\begin{tabular}{|c|c|c|c|}
\hline \multicolumn{4}{|c|}{ Implementation Pyramid } \\
\hline Level & Question & Subject & Characteristic \\
\hline Management & Why? & Policy/Strategy & Abstract \\
\hline Process Design & What? & Plan & Virtual \\
\hline Realisation & How? & Activity & Practical \\
\hline
\end{tabular}

To prioritise improvement activities w.r.t. the maturity of the existing procurement processes and in accordance with the implementation pyramid, it is necessary to structure improvement into different phases. The first phase is the identification of risky procurement elements (i.e. general procurement risks and organisational procurement risks) and improvement metrics (i.e. to track success). This should be followed by the identification of applicable Best Practices and process re-design. In the last phase, the improvements will be implemented and the defined metrics will be used to monitor improvement results to refine the applied practices.

Such an improvement cycle should concentrate on specific areas with defined responsibilities together with an improvement schedule enabling the organisation to realise improvement activities in parallel and/or incrementally. The scope of this approach allows for the use of internal experience and selective application of external methods and guidelines. Furthermore, the approach indicates how external expertise can be integrated to enable an organisation to improve their procurement processes step by step w.r.t. the level of implementation:

- Management: Best Practice Guides (i.e. generic processes and practices).

- Process design: Process Models and Assessment Methodologies.

- Realisation: Application of detailed Best Practices, Templates, Checklists, Evaluation Models or Project Management Tools.

Only by combining different approaches over the implementation levels, applicable improvement opportunities are achievable. 


\section{ACKNOWLEDGEMENTS}

The projects PULSE and VALIDATE are partially funded by the European Commission through the SPRITE S2 Programme Projects No. 97/501155 and 97/501157. The author would like to thank the support of European Commission, and all partner organisations of the PULSE and VALIDATE projects.

\section{REFERENCES}

CCTA (1995), TAP Systems Guide and TAP Services Guide, London.

The PULSE Consortium, (1999), ICT Acquisition Process Assessment Methodology.

ISO/IEC TR 15504-2 (1998), Information Technology - Software Process Assessment - Part 2: A reference model for processes and process capability.

The VALIDATE project partners (1999), VALIDATE Guide - Analysing the impact of IT procurement best practice.

The BuyIT Best Practice Group (1996), Buy-IT Guidelines Chapters 1-11.

EU Member States'IT Public Procurement Group (PPG) (1996) - European Procurement Handbook for Open Systems, Version 1.1.

WEAG TA-13 (1997), EURAP - European Requirements for the Acquisition Process.

Euromethod project (1996), Euromethod Version 1

ISO/IEC 14598-4 (1997), Information Technology - Software product evaluation Part 4 - Process for Acquirers.

WEAG TA-13 (1997), Progressive Acquisition

Department of Defense - DoD (1997), DoD Directive Number R5000.2-R

SEI (1996), SA-CMM - Software Acquisition Capability Maturity Model

Statskontoret (1998), SOTIP Vers.2, The Swedish government open telecommunication systems interconnection profile.

Mottram, R. (1995) CCTA - An evaluation of the Full Implementation of the Total Acquisition Process, http://www.ccta.gov.uk/taprep.htm.

\section{BIOGRAPHY}

Dipl.-Wi.-Ing. Harald Sundmaeker is graduate economic engineer with focus on production technique and industrial management. Since beginning of 1998 member of ATB Institute for Applied Systems Technology Bremen GmbH. He has taken part at different Software Engineering and Procurement projects also funded by the European Community and led several acquisition project assessments as external mentor. His main interests are system analysis and design, quality management and assurance also in the scope of IT procurement projects. 